\title{
Analysis of profitability of using a heat recovery system from grey water discharged from the shower (case study of Poland)
}

\author{
Sabina Kordana ${ }^{1}$, and Daniel Słyś ${ }^{1, *}$ \\ ${ }^{1}$ Rzeszow University of Technology, Department of Infrastructure and Sustainable Development, \\ al. Powstańców Warszawy 6, 35-959 Rzeszów, Poland
}

\begin{abstract}
The paper analyses the profitability of the use of Drain Water Heat Recovery units. An original simulation model was used for this purpose, and a detached residential building located in Poland was selected as the test facility. The conducted analysis proved that the type of the hot water heater has decisive influence on the profitability level of such an investment. Application of the abovementioned technology is particularly profitable, when water is heated with the use of an electrical device. When the energy source in the system is a gas water heater, the obtained calculation results are not as favourable, and the period of investment return in many cases exceeds the expected service life of these devices. Moreover, the analysis demonstrated that the potential energy savings, and thus also the financial savings, may be in both cases increased as a result of simultaneous intake of water from various water taps.
\end{abstract}

\section{Introduction}

The current living standards and the increasing consumerism result in the excessive exploitation of natural resources, including fossil resources, while the gradual depletion of conventional fuels is identified as one of the challenges that the future generations will be faced with. The problem is additionally exacerbated by the climate changes $[1,2]$ which have been observed in recent years and which are enforcing the application of innovative technologies in all facets of life $[3,4]$. In view of that, it is necessary to strive to reduce energy use at particular stages of energy generation, processing and consumption [5-7].

In the case of residential building the energy use in individual buildings can vary widely $[8,9]$. This is because it depends on the size of the building and its type, as well as the demographic characteristics of residents and their income. Not without significance is also the location of the building and its equipment. A significant impact on the energy usage in the household has also the price of individual energy carriers, which also can be of decisive importance in the decision making process for the use of energy-efficient installations.

The above factors affect not only the total energy usage in residential buildings, but also determine the structure of its usage in individual buildings. Recent years have witnessed an increasingly large role of domestic hot water production in the energy consumption

*Corresponding author: daniels@prz.edu.pl 
balance. For developed countries, it represents on average from over a dozen even to several dozen percent of total energy consumption in buildings $[10,11]$, which renders it a perfect subject for scientific research aiming to reduce household energy demand.

The aim of the research described in this article is to determine the cost-effectiveness of installing a Drain Water Heat Recovery (DWHR) unit below the shower in a single-family residential building. Analyses have been carried out for various types of instantaneous water heaters and different shower head water flow rates. The simultaneity of water intake from two water taps has also been taken into account. This allowed for an unequivocal assessment of the cost-effectiveness of adopting the examined system in various functioning conditions.

\section{Theory and calculation}

The idea behind the operation of DWHR unit is the transfer of thermal energy contained in grey water to the incoming cold tap water, and their effectiveness depends primarily on the design of the heat exchanger and the rates of water and drain water flow through the unit [12]. Although scientists from all over the world are engaged in developing new, high-performance structures of DWHR units [13-15], vertical counter-flow heat exchangers are still the subject of most interest, as they are characterized by the highest efficiency of heat recovery, in many cases exceeding 50\%. A big advantage of DWHR heat exchangers is the opportunity of cooperation with devices designed to acquire energy from other unconventional energy sources. For example, in [16] there is a description of the installation, in which water led into the sanitary facilities is heated by DWHR unit and solar collectors. Wallin and Claesson [17], in turn, examined the possibility of cooperation of such heat exchanger with a heat pump.

DWHR heat exchangers predominantly cooperate with instantaneous water heaters, one of the most widely used devices in housing. However, adopting a system for heat recovery from grey water requires a change in the way of routing particular pipes of the internal water and sewage installation in the building, in relation to the traditional solution of such installations, in which cold water is fed both to the shower mixing valve and hot water heater (Variant 0). DWHR units are usually mounted on the outlet of grey water from the shower, and heated while passing through the heat exchanger water is supplied to the hot water heater and/or shower mixing valve. Additionally, we can distinguish two different methods of preparation of domestic hot water supplied to the other points of use where mixed water is used:

- Variant 1 - heating water by using a separate heat source (Fig. 1),

- Variant 2 - heating water by using the same heater, from which the domestic hot water is led to the shower mixing valve (Fig. 2).

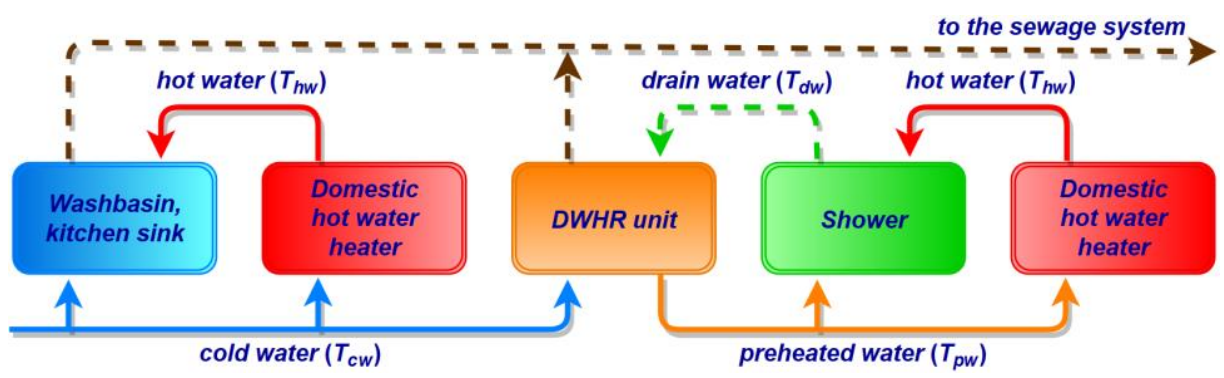

Fig. 1. Diagram of the installation with two hot water heaters (Variant 1).

In order to determine the financial performance of applying a grey water heat recovery system cooperating with the instantaneous electric or gas hot water heater, an original 
simulation model described by Słyś and Kordana [12] was used. In this study, a simplified assumption was made that during the flow of water through the pipes there are no heat losses, so the adopted temperatures are constant over time. In addition, it was assumed that the efficiency of heat recovery from grey water is not determined by the presence of impurities it may contain.

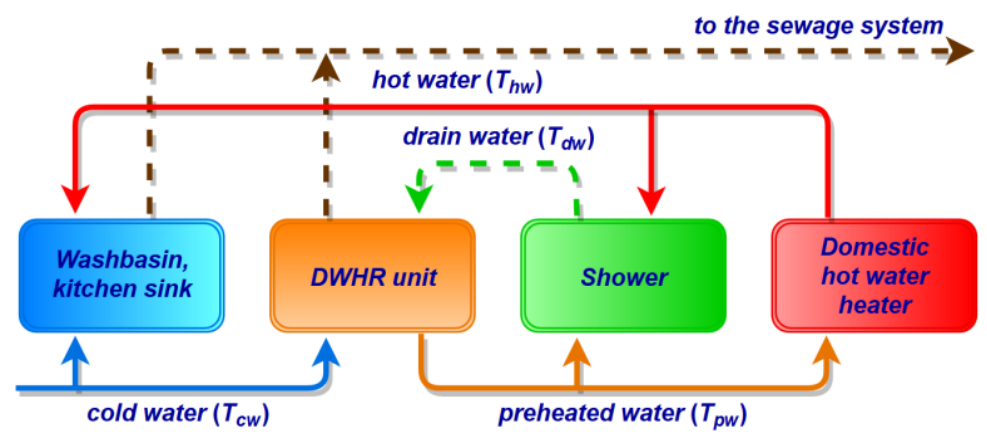

Fig. 2. Diagram of the installation with only one hot water heater (Variant 2).

Numerical model output variables are financial indicators:

- $N P V$ - Net Present Value, $€$,

- $D P P$ - Discounted Payback Period, years.

In the case of grey water heat recovery systems the value of $N P V$ may be defined for a specific time period on the basis of Eq. (1).

$$
N P V=\sum_{t=0}^{n}\left[\frac{S_{t}-I N V_{t}}{(1+r)^{t}}\right]
$$

where: $S_{t}$ - savings in the year $t, € ; I N V_{t}$ - investment in the year $t, € ; r$ - the discount rate; $n$ - number of years of the operation of the system, years.

The value of $D P P$ can be, in turn, determined according to Eq. (2).

$$
D P P=Y+\frac{\left|N P V_{Y}\right|}{C F_{(Y+1)}}
$$

where: $Y$ - the number of full years before the return of investment, years; $N P V_{Y}$ - unrecovered expenditures set at the beginning of the year $(Y+1), € ; C F_{(Y+1)}$ - discounted cash flow in the year $(Y+1), €$.

The analysis was performed for the single-family dwelling house located in Rzeszow. The study assumed that each of the residents is using the shower once a day and the consumption of water and energy for water heating is in the particular case the same for each installation user. To determine the effect of specific parameters of installation using on the results of the study, the calculations were carried out for different number of residents $(R)$, the variable duration of showering $(l)$, and also for different values of the flow rate of water from the shower head $\left(q_{m w}\right)$. The values of these parameters, as well as other data used in calculations, are the following:

- the number of residents $(R): 3,4,5$ persons,

- shower length $(l)$ (to determine $D P P$ ): $3.5 \mathrm{~min}, 6.0 \mathrm{~min}, 8.5 \mathrm{~min}$,

- the flow of mixed water $\left(q_{m w}\right): 6.0 \mathrm{~L} / \mathrm{min}$ or $8.0 \mathrm{~L} / \mathrm{min}$, 
- investment in the year $0\left(I N V_{0}\right): € 900.00$,

- the discount rate $(r): 5 \%$,

- number of years of the operation of the system $(n): 15$ years,

- the price of electricity in the year $0\left(C_{e 0}\right): 0.13 € / \mathrm{kWh}$,

- the price of natural gas in the year $0\left(C_{g 0}\right): 0.04 € / \mathrm{kWh}$,

- annual increase in electricity and natural gas prices $\left(i_{e}\right): 2 \%$,

- the temperature of hot water $\left(T_{h w}\right): 55^{\circ} \mathrm{C}$,

- the temperature of cold water $\left(T_{c w}\right): 10^{\circ} \mathrm{C}$,

- the temperature of mixed water $\left(T_{m w}\right): 40^{\circ} \mathrm{C}$,

- the efficiency of the system in the case of the use of electric water heater $\left(\eta_{e}\right): 0.99$

- the efficiency of the system in the case of the use of gas water heater $\left(\eta_{g}\right): 0.85$.

In the case when the source of energy for water heating are the two independent instantaneous water heaters (Variant 1), the amount of heat recovered from grey water does not depend on taking water from washbasin tap or kitchen sink tap. In a situation where there is only one device designed for hot water heating in the installation (Variant 2), it is necessary to take into account the simultaneity of water intake from two or three points of use. In order to determine the impact of such occurrence on financial efficiency of the investment it was assumed that $80 \%$ of the time of using the heat recovery system only water used for showering needs is heated. In the remaining period of time there is simultaneity of water intake from the two taps. It was assumed that the temperature of mixed water $\left(T_{m w}\right)$ is in both devices the same and the flow rate of water from the mixing valve of the second sanitary facility is equal to $6.0 \mathrm{~L} / \mathrm{min}$.

\section{Results and discussion}

Figure 3 presents the obtained results of calculations of Net Present Value $(N P V)$ and Discounted Payback Period (DPP). The first column (Fig. 3a, 3c, 3e) shows the findings of an analysis carried out for the event that two separate energy sources in the installation are utilised for water heating. Figures $3 b, 3 d$ and $3 f$, in turn, depict the findings of an analogous analysis conducted with an assumption of simultaneous water intake from two different water taps.

The obtained results clearly indicate that the type of hot water heater used has a large impact on the cost-effectiveness of the undertaking that is installation of a DWHR heat exchanger below the shower. The use of a DWHR unit is particularly advantageous when the energy source for heating water is an instantaneous electric hot water heater. In this case the $N P V$ reaches negative value only if the total consumption of water used in the analysed household for the needs of taking a shower is low. In the event the installation has two separate heat sources and daily water consumption for that purpose exceeds $82.0 \mathrm{~L}$ at $q_{m w}=8.0 \mathrm{~L} / \mathrm{min}$, or $75 \mathrm{~L}$ at $q_{w m}=6.0 \mathrm{~L} / \mathrm{min}$, the undertaking is in turn cost-effective, since $N P V>0$.

In a situation where hot water is prepared by a gas heater, the project turned out to be financially advantageous only when the water consumption during taking a shower is high and far exceeds $200.0 \mathrm{~L}$ per day. Therefore, such solution can be applied in the case of shower heads characterized by high mixed water flow rate and also in the case where total time of taking a shower is long.

The differences in received $N P V$ values for particular types of water heaters are the result of differences in the prices of both analysed energy carriers. The price of electricity is so high in comparison with the costs that have to be born for the delivery of natural gas allowing to produce the same amount of thermal energy that, despite the fact that the efficiency of the system for the hot water heating is in the first case by almost 
15 percentage points higher, the costs for the supply of electricity used for hot water heating are much higher than for the supply of natural gas.

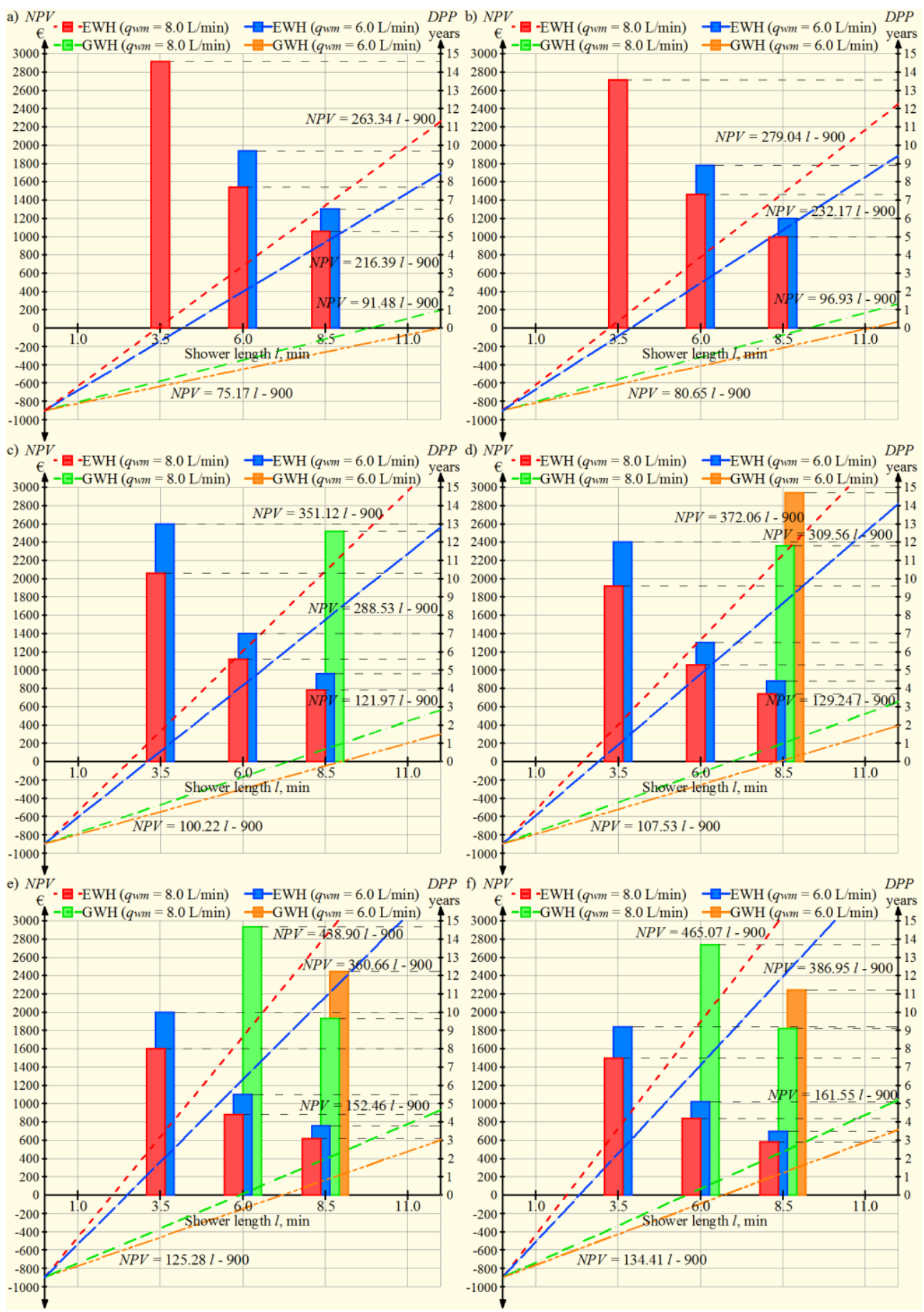

Fig. 3. Summary of results of the calculation of $N P V$ and $D P P: a)$, b) 3 persons; c), d) 4 persons; e), f) 5 persons (EWH - electric water heater, GWH - gas water heater). 
This is reflected in the amount of potential savings, and consequently in the results of calculation of the Net Present Values, which in the case of an electric water heater significantly exceed the values obtained for gas device. The higher the shower head water flow rate, the bigger the difference. For the analysed time interval, differences exceed at times even $€ 2.000,00$.

The amount of recoverable thermal energy was determined on the basis of a graph of the dependence of the energy recovered from grey water on the flow rate of both media (offered by the manufacturer of the analysed heat exchanger). In the situation where in the DWHR unit the water is heated only to be used for the purpose of taking a shower, the flow rates of water and drain water through the heat exchanger are equal, and account for $6.0 \mathrm{~L} / \mathrm{min}$ or $8.0 \mathrm{~L} / \mathrm{min}$, depending on the shower head settings. In the first case taken into consideration $\left(q_{m w}=6.0 \mathrm{~L} / \mathrm{min}\right)$ the amount of heat energy recovered from drain water $\left(E_{r}\right)$ is equal to $7.4 \mathrm{~kW}$. Increasing the water flow through the heat exchanger to $10.0 \mathrm{~L} / \mathrm{min}$, resulting from the intake of water from the other sanitary facilities (Variant 2), causes the increase of the amount of heat recovered from drain water by about $1.0 \mathrm{~kW}$. The temperature of preheated water $\left(T_{p w}\right)$ will be in such a situation lower by almost $6^{\circ} \mathrm{C}$, however, the amount of heated water will increase by nearly $70 \%$, making the final energy demand to be reduced, and the financial performance of the project will be higher than the efficiency obtained from water consumption only from the shower.

The analysis also demonstrated that the potential savings can be increased as a result of simultaneous intake of water from two different water taps. It should be noted, however, that the Net Present Values characterizing Variant 2 are just slightly higher than those obtained with the assumption that only water used for the purpose of taking a shower flows through the heat exchanger. It is clear that in the analysed case, the way the water is heated has a marginal impact on financial efficiency of a project involving the installation of the DWHR unit. For this reason, it should not be the determinant of the decision of using a heat recovery system from grey water.

Also, in the case when mixed water flow $\left(q_{m w}\right)$ is equal to $8.0 \mathrm{~L} / \mathrm{min}$, the simultaneity of water intake from two sanitary facilities results in the increase of the amount of heat recovery. The temperature of preheated water $\left(T_{p w}\right)$ is in this case lower by $4.2^{\circ} \mathrm{C}$, which is the result of a minor proportion of water used in the second device in comparison with the previous case, but the predicted increase in the $N P V$ values is comparable. In the described situation, simultaneous use of the third device is not advisable, as the water flow rate through the heat exchanger would reach a value which is not included in the graph characterizing the analysed heat exchanger. The lack of available characteristics for such values of water flow through the device can be tantamount to a sharp decrease of its effectiveness. The solution to this problem may be, however, to change the way of water pipes routing, which means supplying water only to the domestic hot water heater. Shower mixing valve would be in this case supplied with cold water, which would allow reducing the amount of water transported through the heat exchanger.

The Discounted Payback Period $(D P P)$ was designated for shower length $(l)$ of $3.5 \mathrm{~min}$, $6.0 \mathrm{~min}$ and $8.5 \mathrm{~min}$, but only for those investment options for which the $N P V$ reaches positive values, as in other cases its length exceeds the technical lifetime of the device (Fig. 3). It is evident that the value of $D P P$ is determined by the amount of water used for the needs connected with taking a shower and the type of device used to heat water. It is also easy to note that the $D P P$ value decreases with the increase of the Net Present Value of the project.

In order to assess the investment risk associated with the use of a heat recovery system from grey water discharged from the shower in the single-family dwelling house, the investment sensitivity analysis was also performed [18]. The study was conducted for the case where the shower length for one person is 6.0 minutes, and the shower is used by 
4 people. It was assumed that in the heat exchanger only water used for the purpose of taking a shower is heated.

The conducted analysis was based on the determination of the investment sensitivity indexes $(w w)$, showing how huge impact on the received $N P V$ value has a change in the value of individual independent variables by $1 \%$, and the relative safety margins $\left(s_{m r}\right)$, defining the permissible deviation of the variable from the base value, where the project remains profitable. It was additionally found how the level of profitability of the analysed project will change in the situation when the given independent variable will change by a specific percentage value.

The values of the sensitivity indexes $(w w)$ and the relative safety margins $\left(s_{m r}\right)$ were determined for those cases for which the $N P V$ reaches positive values, which indicates the profitability of the analysed project. The summary of the results of these calculations is presented in Table 1.

Table 1. The results of sensitivity analysis for the case when water is heated by electricity.

\begin{tabular}{|c|c|c|}
\hline The analysed independent variable & Sensitivity index $(\boldsymbol{w w})$ & Relative safety margin $\left(\boldsymbol{s}_{\boldsymbol{m} r}\right)$ \\
\hline \multicolumn{2}{|c|}{ Water flow from the shower head $q_{m w}=6.0 \mathrm{~L} / \mathrm{min}$} \\
\hline Investment & -1.08 & $92.33 \%$ \\
\hline Electricity prices & 2.08 & $-48.01 \%$ \\
\hline \multicolumn{2}{|c|}{ Water flow from the shower head $q_{m w}=8.0 \mathrm{~L} / \mathrm{min}$} \\
\hline Investment & -0.75 & $134.07 \%$ \\
\hline Electricity prices & 1.75 & $-57.28 \%$ \\
\hline
\end{tabular}

The sensitivity analysis showed that in the case of electric hot water heater the level of profitability of the project is only slightly determined by the values of the analysed independent variables. It is also worth pointing out that the sensitivity of the undertaking to changes of installation operating costs is higher than to changes in investment outlays, as evidenced by the higher absolute value of the sensitivity index and the smaller safety margin. In addition, the difference in sensitivity indexes values calculated for both of the independent variables increases when the shower head water flow rate decreases. It is the consequence of reducing the basic value of the $N P V$ with the decrease of water consumption while maintaining the same duration of taking a shower.

The observations above are also verified by the results of a research that assumed changes in values of the analysed independent variables by specific percentages, the results of which are shown in Figure 4. A change in the values of those variables even by $35 \%$ will not, in the case of an electric water heater, cause a decrease of the $N P V$ value to below zero.

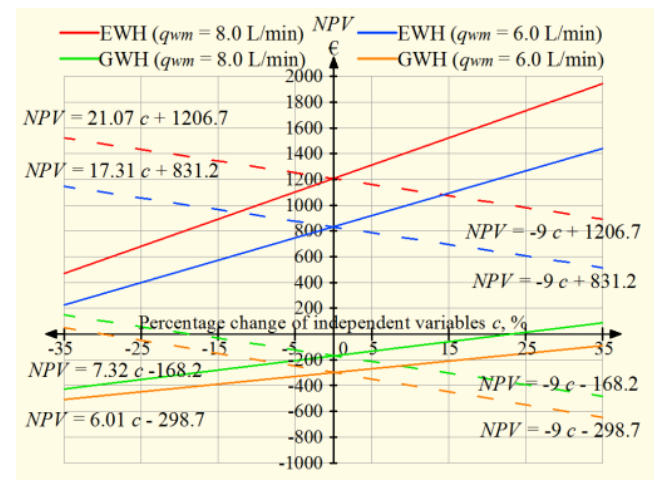

Fig. 4. Graphical form of sensitivity analysis for variables linearly changing return on investment (solid line - electricity/gas prices changes, dashed line - investment changes). 
In the case of a gas hot water heater, where the basic value of the $N P V<0$, the undertaking would become cost-effective only when the investment outlays were decreased to $€ 601.00$ and $€ 732.00$, respectively for shower heads with flow rates of $6.0 \mathrm{~L} / \mathrm{min}$ and $8.0 \mathrm{~L} / \mathrm{min}$. Energy prices, in turn, would have to increase by $50 \%$ and $23 \%$ respectively.

\section{Conclusions}

The conducted financial analysis of the application of a DWHR unit cooperating with various types of instantaneous water heaters in a single-family residential building has demonstrated a large impact of operating parameters of the installation on the undertaking cost-effectiveness. In view of that, there is a need to emphasise the necessity of carrying out a thorough technical and financial analysis for each case of adoption of this solution.

The results of the analysis of financial efficiency of the investment, which were received by using the developed calculation model, can serve as a guide when deciding on the application of the system described in the article, both for individual users of internal installations and for the designers of this type of installation.

\section{References}

1. B. Kaźmierczak, A. Kotowski, Theor. Appl. Climatol. 118, 285-296 (2014)

2. M. Starzec, J. Dziopak, M.I. Alexeev, Water and Ecology 1, 41-50 (2015)

3. K. Pochwat, D. Słyś, J. Dziopak, Installation of retention facilities (EP 15461517.3, 2011)

4. M. Zeleňaková, G. Markovič, D. Kaposztásová, Z. Vranayová, Procedia Eng. 89, 1515-1521 (2014)

5. M.A. Sayegh, J. Danielewicz, T. Nannou, M. Miniewicz, P. Jadwiszczak, K. Piekarska, H. Jouhara, Renew. Sustain. Energy Rev. 68, 1183-1192 (2017)

6. A. Stec, S. Kordana, Resour. Conserv. Recycl. 105, 84-94 (2015)

7. M.H. Wahlström, B. Hårsman, Energy Build. 102, 58-66 (2015)

8. A.N. Binks, S.J. Kenway, P.A. Lant, B.W. Head, J. Clean. Prod. 135, 892-906 (2016)

9. J.L. Reyna, M.V. Chester, S.J. Rey, Energy 112, 742-754 (2016)

10. A. Bertrand, R. Aggoune, F. Maréchal, Appl. Energy 192, 110-125 (2017)

11. A. Bertrand, A. Mastrucci, N. Schüler, R. Aggoune, F. Maréchal, Appl. Energy 186, 152-166 (2017)

12. D. Słyś, S. Kordana, Energy Build. 71, 1-11 (2014)

13. S. Bartkowiak, R. Fisk, A. Funk, J. Hair, S.J. Skerlos, J. Green Build. 5, 85-94 (2010)

14. S. Morales-Ruiz, J. Rigola, C. Oliet, A. Oliva, Appl. Energy 179, 1006-1019 (2016)

15. E. Tian, Y.L. He, W.Q. Tao, Appl. Energy 188, 586-594 (2017)

16. K. Tanha, A.S. Fung, R. Kumar, Appl. Therm. Eng. 90, 444-459 (2015)

17. J. Wallin, J. Claesson, Energy Build. 80, 7-16 (2014)

18. W. Rogowski, Rachunek efektywności inwestycji (Wolter Kluwer, Cracow, 2008) 